\title{
IBM PENINGKATAN PENYAJIAN MUSIK BIA KELOMPOK ANAK DI DESA BATU
}

\author{
Glenie Latuni ${ }^{1}$, R.A.D Sri Hartati ${ }^{2}$ \\ 1 Prodi Pendidikan Sendratasik Fakultas Bahasa dan Seni \\ Universitas Negeri Manado \\ Email : glenielatuni@unima.ac.id \\ 1 Prodi Pendidikan Sendratasik Fakultas Bahasa dan Seni \\ Universitas Negeri Manado \\ Email : Dinar_srihartati@yahoo.com
}

\begin{abstract}
The purpose of this activity is to improve the presentation of Bia Music Child Group in Batu Village Likupang Selatan North Minahasa Subdistrict. By using the method of music blowing without reed training is implemented. The target of the training are: Position of blower body, Hand position, Respiration, Ambasir, Intonation, Articulation, Engineering penjari. Conclusion Although Bia's music takes on traditional music, but in developing it must be done with the correct technique.
\end{abstract}

Keywords: Improved Presentation, Music Bia Group of Children 


\section{PENDAHULUAN}

Setiap kelompok masyarakat mempunyai Kesenian sebagai alat apresiasi. Apresiasi itu dapat dilakukan dengan menggunakan berbagai media salah satunya lewat media bunyi yang disebut musik. Walaupun awalnya Bia digunakan masyarakat sebagai sarana ritual dan sebagai alat komunikasi masyarakat. Tetapi kemudian berubah fungsinya menjadi karya seni (Hastanto, 2005). Bia yang dijaidkan alat musik adalah Bia Kepala Kambing atau helmet, (Cassis Cornuta Linneaus), Bia Conch Ratu (Strombus Cigas Linneaus), Bia Helmet Raja atau Cassis Tuberosa Linneaus, Bia Trompet (Triton Trompet) yang dikenal dalam bahasa latin, yaitu Haroni a Riton Linneaus.

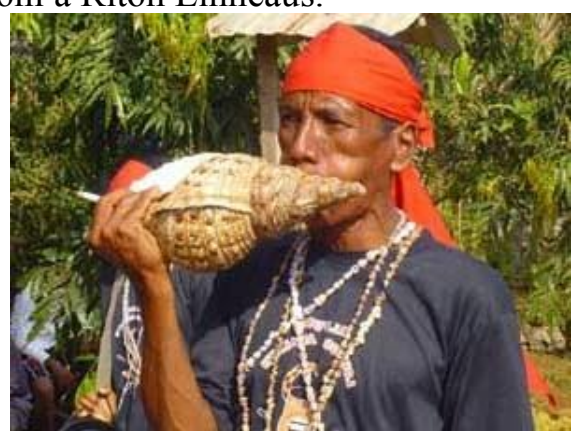

Gambar 1. Bia berfungsi sebagai alat Ritual

Di Desa Batu- Likupang Selatan terdapat tiga kelompok musik Bia, yaitu: Mutiara Batu, Permata Laut, dan Mutiara Kasih. Kelompokkelompok sudah sering tampil dalam berbagai event pertunjukan. Keberadaan musik ini mampu mendorong anak-anak di desa tersebut untuk mengapresiasi dan mendapatkan pengalaman bermusik. Seperti kata Rohidi musik pada hakekatnya dapat juga berfungsi sebagai sarana pendidikan dalam hal ini musik digunakan untuk meningkatkan dan mengembangkan potensi rasa keindahan peserta didik melalui pengalaman dan penghayatan musik, kemampuan mengungkapkan dirinya melalui musik, kemampuan menilai musik melalui selera intelektual dan artistik, sehingga memungkinkan peserta didik dapat mengembangkan kepekaan terhadap dunia disekelilingnya serta dapat meningkatkan pengetahuan dan kemampuan dalam bidang musik. Mulai dari pengenalan bunyi, struktur dan elemen-elemen yang terdapat dalam alat musik tersebut, unsur-unsur musik yang terkandung didalamnya, pembentukan nilai-nilai emosional, serta proses pengembangan intelegensi dan motorik peserta didik, semuanya terangkum dalam suatu bingkai musik itu. (Rohidi,2000)

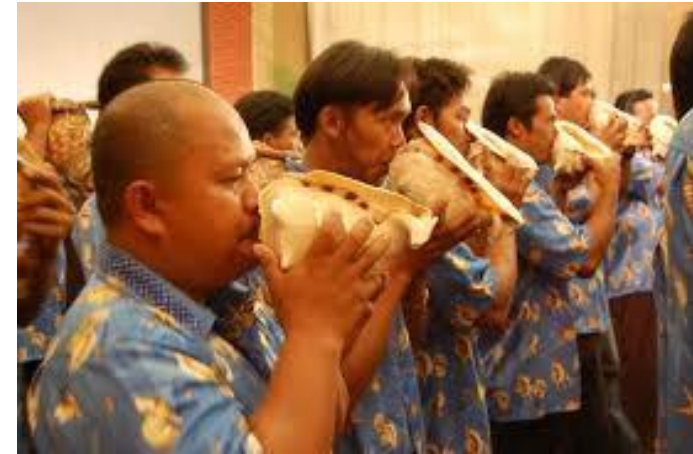

Gambar 2. Musik Tradisional Bia Desa Batu

Melalui musik anak-anak dapat mengungkapkan bahasa emosi yang bersifat universal. Kemampuan untuk dapat mengungkapkan emosi melalui musik ini merupakan keterampilan yang unik terhadap perasaan. Dengan musik, anak-anak dapat mengungkapkan perasaan pribadinya, meskipun tanggapan terhadap ungkapan perasaan melalui musik ini akan berbeda antara seorang dengan yang lain. Mereka menanggapi musik dengan intuisinya, tetapi tingkat mutu tanggapannya itu tergantung kepada pengetahuan dan pengertiannya tentang unsur-unsur musik. Hal tersebut harus senantiasa ditanamkan, dipupuk, ditingkatkan, dan dikembangkan dalam pengajaran musik karena merupakan hal yang sangat esensial untuk dapat memahami musik.

Mendengarkan, bernyanyi, bermain musik, bergerak mengikuti irama musik, serta membaca notasi musik adalah bentuk-bentuk kegiatan pengalaman musik anak didik yang menopang fungsi dan peran musik tersebut. Selain itu, yang tidak kalah pentingnya juga adalah bagaimana pembentukan kreativitas musik anak didik untuk dapat berperan dalam interaksi pembelajaran. Penguasaan terhadap unsur dan alat musik akan dapat memacu semangat dan kemampuan untuk dapat berkompetisi secara bersama dengan komunitas peserta didik yang lainnya. Dengan demikian, maka musik menjadi salah satu elemen dalam kehidupan manusia yang memberi peran besar terhadap pembentukan sifat dan karakter serta unsur psikomotorik anak didik.

Untuk menjaga keberadaan musik tradisional Bia tetap hidup dan berkembang di Kabupaten Desa Batu- Likupang, maka Universitas Negeri Manado mengadakan kegiatan IBM Pada Musik Biaya kelompok anak di Desa Batu, diharapkan terjadi regenerasi dalam kelompok Musik Bia di Desa Batu dan musik ini lestari dan menjadi sumber ekonomi kreatif ke depan. 


\section{RUMUSAN MASALAH}

Melihat permasalahan maka kami mengadakan kegiatan pengabdian masyarakat yakni Pengembangan kelompok Musik Bia pada anak-anak di Desa Batu.

\section{METODE PELAKSANAAN Metode Pelatihan}

Karena belum adanya sumber tertulis metode peniupan Musik Bia maka saya mencoba menggunakan metode peniupan musik tanpa reed yang dikemukakan oleh Agus Untung Yulianto. Metode tiup dalam hal ini yang dimaksud adalah penguasaan teknik dasar permainan instrumen tiup logam maupun kayu untuk tingkat dasar, yang mana mempunyai pengertian berbagai hal yang berhubungan dengan cara bermain instrumen, pengertian organologi, maupun apresiasi musik tiup, dan hal tersebut merupakan tahapan awal/dasar instrumen tiup logam dan kayu, sedangkan ciri-ciri yang dimaksud dengan instrumen tiup logam.

Instrumen biasanya seluruh body yang terbuat dari logam, atau campuran antara logam dan fiber. Mouthpiece terbuat dari logam yang berbentuk silinder, dan tidak memakai reed (terbuat dari kayu) dalam memproduksi nada.

Intonasi/produksi nadanya melalui klep/valves maupun slide. Untuk mengulas lebih lanjut metode klas tiup, maka unsur yang paling utama adalah teknik dasar permainan instrumen tiup logam dapat dibagi menjadi tujuh bagian, yaitu : Posisi tubuh pada waktu meniup instrument; Posisi tangan pada waktu memegang instrument; Pernafasan; Ambasir; Intonasi; Artikulasi; Teknik penjarian.

\section{Posisi Tubuh Peniup}

Keberhasilan seseorang dalam bermain instrumen meniup dapat ditentukan dengan posisi tubuh ataupun sikap tubuh., sedangkan sikap tersebut di atas dapat dilakukan dengan cara berdiri maupun duduk, yaitu : Posisi berdiri pada waktu bermain instrumen tiup logam, hendaknya tubuh tegak lurus muka menghadap ke depan serta posisi instrumen/mouthpiece sejajar dengan muka, kedua belah kaki berdiri secara wajar dan sopan.

Posisi duduk pada waktu bermain instrumen tiup logam, usahakan tubuh tegak lurus di tempat dan muka menghadap ke depan serta posisi instrumen sejajar dengan muka, kedua belah kaki terletak di depan dengan sikap yang wajar dan sopan. Dengan posisi tersebut di atas akan memperlancar jalannya pernafasan dan dapat menguatkan otot-otot di sekitar perut, abdominal serta diafragma, sehingga udara yang dihirup maupun dihembuskan/ditiup akan lebih banyak serta nada-nada yang dihasilkan menjadi lebih jelas.

\section{Posisi Tangan Peniup}

Bentuk permainan instrumen tiup logam sangat ditentukan baik dengan pernafasaan maupun skill, sehingga fungsi tangan kanan dan tangan kiri tidak hanya digunakan untuk memegang atau menggerakkan klep/valves maupun slide, tetapi lebih dari itu ialah sebagai penunjang teknik permainan secara baik dan benar, sehingga dapat meningkatkan ketrampilan secara optimal. Sedangkan cara memegang instrumen tiup logam adalah sebagai berikut :

Tangan kiri pemain berfungsi sebagai pemegang body instrumen yang mencakup tiga buah tabung klep/valves dengan menggunakan tiga buah jari tangan (jari telunjuk, jari tengah, dan jari manis) usahakan tangan kiri tidak menekan ke arah ambasir dan dalam keadaan rileks serta sejajar dengan muka.

Tangan kanan berfungsi sebagai pengatur ketiga buah klep/valves dalam hubungannya dengan fingering atau penjarian yang menggunakan tiga buah ujung jari dan diletakkan di atas papan klep/valves. Usakan ketiga buah jari tangan kanan tersebut di atas selalu dalam keadaan rileks dan membentuk suatu lengkungan (seperti memegang bola tenis), sehingga pada waktu diperlukan dapat bergerak secara fleksibel dan lancar baik dalam gerakan lambat maupun cepat, serta dapat menahan goncangan apabila sedang memainkan instrumen.

\section{Teknik Pernapasan.}

Pengertian pernafasan dalan instrumen tiup adalah cara pengaturan pernafasan yang diperlukan untuk memproduksi nada-nada dari instrumen tiup, dan pernafasan diafragma, abdominal rongga-rongga perut bagian samping kiri/kanan serta ronga dada (di mana tepat pada ulu hati terasa lebih mengembang waktu mengambil nafas), dan hal tersebut merupakan kunci keberhasilan permainan instrumen tiup baik logam maupun kayu , sehingga akan menghasilkan karakter warna nada sesuai instrumennya. Ada beberapa bentuk pernafasan yang sering dilakukan manusia, yaitu pernafasan bahu, dada, perut dan pernafasan diafragmatis. 
Dalam hal ini penulis hanya akan mengkaji suatu bentuk pernafasan yang paling baik untuk digunakan dalam permainan instrumen tiup, yaitu pernafasan diafragmatis. Pernafasan Diafragmatis. Pernafasan diafragmatis adalah proses pernafasan dengan memasukkan udara melalui sudut-sudut kanan dan kiri bibir pemain ke dalam paru-paru ( seperti minum pakai sedotan ). Pada waktu menghirup udara, otototot perut bagian samping kanan dan kiri ikut mengembang (pernafasan diafragmatis) serta otot-otot di sekitar perut ikut membantu menekan udara dari dalam paru-paru, sehinggar udara di dalamnya mendapat tekanan tambahan, dan masuk ke rongga abdominal maupun rongga dada. Sedangkan cara mendapatkan pernafasan diafragmatis adalah sebagai berikut di bawah ini

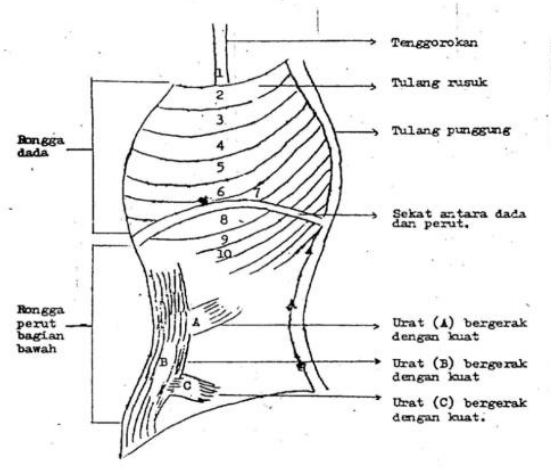

Gambar ini menunjukkan fungsi pernafasan diafragma dan bagian dari posisi otot-otot perut samping kakan, kiri dalam pernafasan yang tepat. Sekat antara dada dan perut yang bergaris tebal itu adalah suatu kubuh yang berbentuk rangka urat yang terletak kira-kira di tengah-tengah anggota badan terpisah dari pada dada dan rongga perut (pengembangan ulu hati).

Posisi badan dalam keadaan berdiri kemudian dibungkukkan kurang lebih 90 derajat dan kedua telapak tangan memegang perut pada bagian samping kanan dan kiri, sehingga terasa ada desakan udara ke arah diafragmatis maupun otototot di sekitar samping perut kanan dan kiri, kemudian diarahkan ke luar melalui lubang bibir yang dikatupkan sekaligus membentuk huruf "U". Selanjutnya udara yang bergetar tersebut dimasukkan ke dalam instrumen tiup logam melalui mouthiece, sehingga udara yang bergetar tersebut akan menjadi nada-nada instrumen tiup logam sesuai dengan karakter produksi nada yang dikehendaki.

Posisi badan dalam keadaan duduk, kemudian bungkukkan ke depan sehingga dada terasa menempel pada kedua belah paha dan peganglah perut pada bagian samping kanan dan kiri serta rasakan adanya udara yang menekan dari dalam perut ke arah abdominal.

\section{Ambasir}

Pengertian ambasir di sini adalah bentuk bibir yang dikaitkan dengan penggunaan mouthpiece pada masing-masing instrumen, dan menggambarkan cara meniup instrumen tiup agar dapat menghasilkan nada-nada yang tepat, baik dan benar dengan memanfaatkan otot-otot bibir, dagu, pipi, gigi, rahang, rongga mulut dan tenggorokan pemainnya. Kekuatan otot-otot tersebut dapat dilatih dengan cara, fungsikan secara maksimal bibir membentuk "U" kemudian rapatkan gigi seri atas, bawah dan letakkan/masukkan sebuah pensil sampai menempel gigi seri, serta katupkan bibir dengan mengencangkan otot-otot sudut bibir kanan, kiri sehinga terasa seluruh otot-otot wajah berfungsi dalam meningkatkan kemampuan mengolah ambasir secara total.

Setelah dapat mempraktekkan maka setiap pemain diharapkan mampu memproduksi nada-nada yang dikehendaki/dicapai sesuai dengan batas kemampuan-nya. Apabila pemain menginginkan nada dengan register tinggi, maka cukup mengencangkan otot-otot di sekitar lobang bibir dan mengencangkan sudut kanan, kirinya, yang mana kondisi tersebut menyebabkan getaran bibir menjadi lebih cepat, serta mengakibatkan/menjadikan lubang bibir menyempit sehingga dapat memproduksi nada-nada tinggi.

Keberhasilan pemain instrumen tiup logam maupun kayu sangat didukung oleh ketahanan fisik dan fleksibilitas pemain, dan hal tersebut dapat dibentuk melalui latihan secara rutin dan intensif dengan berbagai cara yang antara lain adalah : Dengan menggunakan mouthpiece saja sebagai permulaannya dan pada waktu

meniup kedua belah bibir ditempelkan ke lubang mouthpiece, sehingga bibir bawah bagian dalam yang berwarna merah terasa ada getaran serta posisi 
mouthpiece antara kedua belah bibir tiga berbanding dua.

Pada waktu meniup posisi gigi atas dan bawah menjadi rata serta membuka sedikit dalam bentuk posisi "U", sehingga udara dari dalam dapat keluar dengan lancar tanpa terhalang oleh terkatupnya gigi dan ketika mengeluarkan udara dari lubang bibir yang sudah berbentuk oval harus secara kontinyu dan lurus ke depan.

Penempatan mouthpiece pada bibir merupakan suatu hal yang perlu diperhatikan oleh setiap pemain instrumen tiup logam maupun kayu dalam mencapai keberhasilan permainannya. Penempatan mouthpiece tersebut di atas pada dasarnya memanfaatkan ketentuan-ketentuan sebagai berikut : Mouthpiece terletak di tengahtengah bibir pemain, diantaranya sudut mulut kanan dan kiri. Pada umumnya perbandingan letak mouthpiece pada bibir atas dan bawah adalah $3: 2$.

Mouthpiece tidak boleh menekan permukaan bibir bagian luar sehingga proses produksi nadanya berlangsung secara wajar, di samping itu juga tidak ada distorsi nada yang dihasilkan.

\section{Intonasi}

Dalam permainan musik perkataan intonasi diartikan sebagai ketetapan tinggi nada atau pitch. Intonasi dalam instrumen tiup memiliki berbagai problem dan ini dapat diketahui pada nada-nada overtone series atau nada-nada atas yang dimiliki nada dasarnya, baik itu terdapat pada instrumen tiup logam maupun kayu serta baik klep atau valves maupun slide.

\section{Artikulasi}

Pengertian artikulasi dalam instrumen tiup adalah bagaimana memproduksi nadanada dengan jelas bersih, baik dan benar. Adapun dalam permainan instrumen tiup dapat dilakukan dengan pemanfaatan ujung lidah pemain, antara lain seperti pada ucapan suku kata 'ta' atau 'ka'. Sedangkan penggunaan artikulasi dapat diterangkan sebagai berikut : Latihan artikulasi dalam bentuk permainan staccato dan legato, pengertian tersebut tidak dapat disamakan dengan bunyi pendek yang dihasilkan tanpa resonansi, bagaimanapun pendek nada yang dihasilkan harus menghasilkan artikulasi dengan jelas, baik menggunakan teknik staccato maupun legato. Contoh penggunaan artikulasi staccato pada instrument tiup.

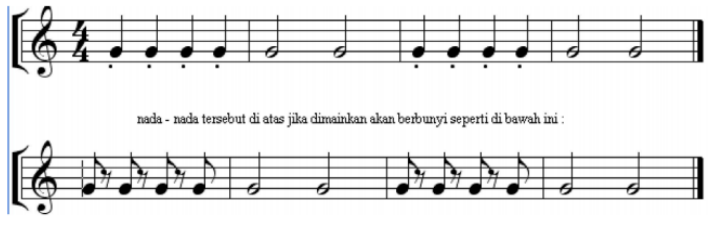

Contoh penggunaan artikulasi legato pada instrument tiup logam

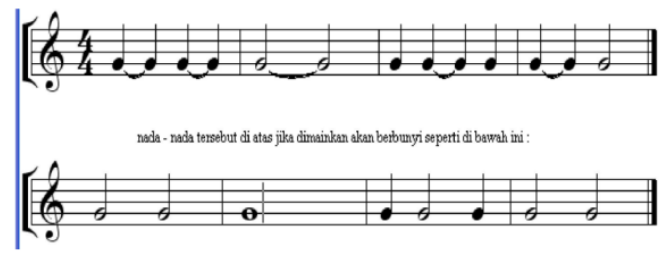

\section{TEKNIK PENJARIAN}

Pengertian teknik penjarian dapat diartikan sebagai kemampuan jari pemain dalam menentukan posisinya terhadap permainan nadanada yang hendak diproduksi. Dengan demikian pemain terlebih dahulu harus mengenal secara jelas posisi dan kegunaan jari-jari tangan kanan/kiri sesuai dengan pembentukan nada-nadanya. Posisi jari pada tangan kiri digunakan untuk memegang instrument, sedangkan jari tangan kanan dipakai sebagai penjarian (terutama pada instrument tiup logam) tersebut adalah jari telunjuk terletak pada klep pertama, jari tengah terletak pada klep kedua, jari manis terletak pada klep ketiga. Sesuai dengan penjelasan di atas untuk memproduksi nada yang bermacam-macam dapat digunakan variasi penjarian klep seperti tersebut di bawah ini :

\section{HASIL DAN PEMBAHASAN}

Kegiatan Ibm Ini dilaksanakan di Desa Batu Kecamatan Likupang Tengah Kabupaten Minahasa Utara. Kegiatan atas dilaksanakan di Balai Desa Batu ini, dihadiri oleh para kelompok Musik Bia senior dan juga kelompok junior/anak-anak. Adapun tujuan umum kegiatan ini untuk memberikan pelatihan dan pendampingan agar grup musik di Desa Batu bisa berkembang menjadi grup musik yang berbasis ekonomi kreatif. Adapun kegiatan ini pada saat ini yakni mengganakan Pelatihan Dasar Peniupan Musik Bia kepada anak-anak.

\section{Posisi tubuh pada waktu meniup}

Posisi Tubuh yang paling saat berdiri hendaknya tubuh tegak lurus muka menghadap ke depan serta posisi instrumen/mouthpiece 
sejajar dengan muka, kedua belah kaki berdiri secara wajar dan sopan. Demikian Juga posisi duduk usahakan tubuh tegak lurus di tempat dan muka menghadap ke depan serta posisi instrumen sejajar dengan muka, kedua belah kaki terletak di depan dengan sikap yang wajar dan sopan. Posisi tersebut di atas akan memperlancar jalannya pernafasan dan dapat menguatkan otot-otot di sekitar perut, abdominal serta diafragma, sehingga udara yang dihirup maupun dihembuskan/ditiup akan lebih banyak serta nada-nada yang dihasilkan menjadi lebih jelas

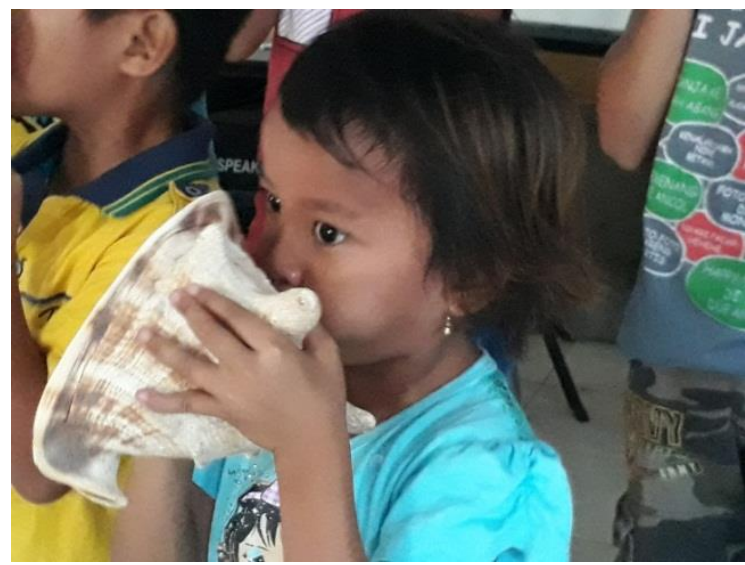

Gambar 3. Posisi tangan pada waktu memegang instrument.

Posisi yang baik saat memengang Bia adalah Tangan kiri pemain berfungsi sebagai pemegang alat Musik Bia dan tangan kanan berfungsi untuk fingering atau penjarian usahakan jari tangan kanan selalu dalam keadaan rileks sehingga pada waktu diperlukan dapat bergerak secara fleksibel dan lancar baik dalam gerakan lambat maupun cepat.

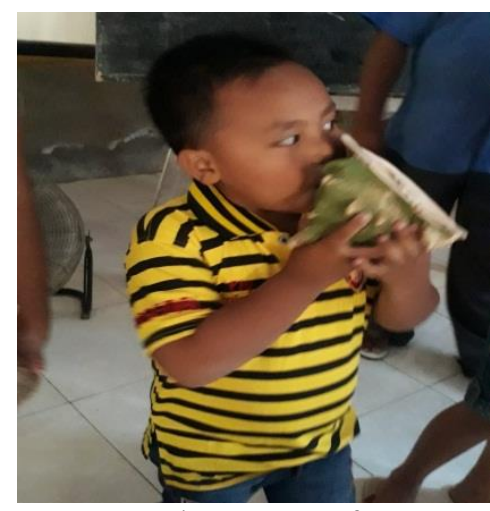

Gambar 4. Pernafasan dan Latihan Ambasir

Pernapasan yang paling baik untuk digunakan dalam permainan instrumen tiup, yaitu pernapasan diafragmatis. Pernafasan
Diafragmatis adalah proses pernafasan dengan memasukkan udara melalui sudut-sudut kanan dan kiri bibir pemain ke dalam paru-paru (seperti minum pakai sedotan). Pada waktu menghirup udara, otot-otot perut bagian samping kanan dan kiri ikut mengembang (pernafasan diafragmatis) serta otot-otot di sekitar perut ikut membantu menekan udara dari dalam paru-paru, sehinggar udara di dalamnya mendapat tekanan tambahan, dan masuk ke rongga abdominal maupun rongga dada.

Pada Musik Bia ambasir atau bentuk bibir yang dikaitkan dengan penggunaan mouthpiece agar menghasilkan nada-nada yang tepat, baik dan benar dengan memanfaatkan otototot bibir, dagu, pipi, gigi, rahang, rongga mulut dan tenggorokan pemainnya.

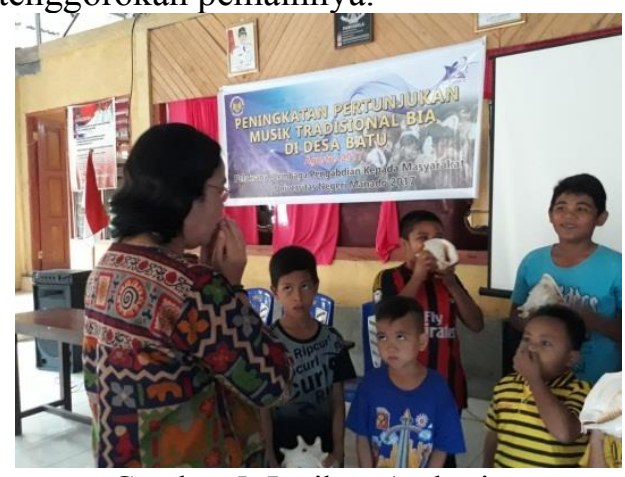

Gambar 5. Latihan Ambasir

\section{Intonasi dan Artikulasi dan sistem penjarian}

Intonasi diartikan sebagai ketetapan tinggi nada atau pitch. Intonasi dalam Musik Bia memiliki problem hal ini kajian khusus, frekuensi bunyi yang tidak stabil, sistem bunyi yang belum baku membuat perlu kajian mulai sistem penalaan, proses bunyi, dan sistem pemilihan lagu. Untuk memproduksi nada dengan jelas bersih, baik dan benar seperti pada intonasi perlu dikaji sistem yang baik karna artikulasi kurang stabil. Demikian juga dengan sistem penjarian perlu di teliti dari sumber awalnya.

\section{KESIMPULAN}

Pelatiahan musik bisa berjalan dengan baik, walau harus segera dibuat kajian dan pelatihan yang bersinambungan agar Musik Bia di Desa Batu bisa berkembang.

\section{REFERENSI}

Agus Untung Yulianta, 2006. Diktat Mata kuliah Kelas Tiup, Jurusan Seni Musik FBS, Universitas Negeri Yogyakarta. 
Edmund Prier, Karl, 1996 "Ilmu Bentuk Musik", Pusat Musik Liturgi, Yogyakarta.

Hastanto, Sri, 2005 Musik Tradisi Nusantara. Jakarta: Direktorat Jenderal Kebudayaan.

Hauser, Arnol, 1982. The Sociology of Art. (Terj. Kenneth J. Northcott Chicago and London: The University of Chicago Press.

Hurlock, Elizabeth B. 2000.

Perkembangan Anak, Penerbit
Erlangga, Jakarta.

Kartono, Kartini, 1986. Psikologi Anak, PT Raja Grafindo Persada, Jakarta.

Laurer, Robert, H., 1993. Perspektif Tentang Perubahan Sosial. Bhineka Cipta Jakarta:

Rohidi, Kesenian Dalam Pendekatan Kebudayaan. Bandung: STSI. 2000. 